\title{
Use and acquisition of mouth actions in L2 sign language learners
}

\author{
A corpus-based approach
}

\author{
Johanna Mesch and Krister Schönström \\ Stockholm University
}

This article deals with L2 acquisition of a sign language, examining in particular the use and acquisition of non-manual mouth actions performed by L2 learners of Swedish Sign Language. Based on longitudinal data from an L2 learner corpus, we describe the distribution, frequency, and spreading patterns of mouth actions in sixteen L2 learners at two time points. The data are compared with nine signers of an L1 control group.

The results reveal some differences in the use of mouth actions between the groups. The results are specifically related to the category of mouthing borrowed from spoken Swedish. L2 signers show an increased use of mouthing compared to L1 signers. Conversely, L1 signers exhibit an increased use of reduced mouthing compared with L2 signers. We also observe an increase of adverbial mouth gestures within the L2 group. The results are discussed in relation to previous findings, and within the framework of cross-linguistic influence.

Keywords: mouth actions, second language acquisition, corpus-based study, Swedish Sign Language

\section{Introduction}

This article deals with the acquisition of a sign language (SL) as a second language (L2). Studies of SL as an L2 are relatively rare, despite the long tradition of teaching $\mathrm{L}_{2}$ learners of SL in some countries. In fact, very little is known about what learning a new language in a new modality is all about. Research on SLs as L2s opens up the opportunity to contribute to our understanding of the mechanisms behind learning a new language through a new modality, i.e., the gestural-visual modality as opposed to the vocal-aural modality. For example, sign languages have been described as having a form of simultaneity in production lacking in 
spoken languages. Linguistically, this can be manifested through the simultaneous production of mouth actions (i.e., mouth movements) and manual components (hands). This simultaneous production is thus something that $\mathrm{L}_{2}$ learners of sign language need to acquire.

Even if most sign linguists would agree that mouth actions obviously constitute a prominent part of sign languages, the scope of their linguistic role is still under debate (Johnston, van Roekel \& Schembri 2016). Studies on L2 learners' use of mouth actions have the potential to contribute new and interesting insights to the discussion regarding the general linguistic status of mouth actions, for example, how the different mouth categories are acquired and used by $\mathrm{L}_{2}$ learners. This would in turn contribute to our understanding of how non-manual features, in this case mouth actions, are acquired by L2 learners and used in comparison to L1 signers.

A considerable number of the mouth actions used in Swedish Sign Language, Svenskt teckenspråk (henceforth STS) are mouthings; that is, based on borrowings from spoken Swedish. In this context, and from an L2 perspective of learning, this is an interesting feature, given the fact that the L2 learners' L1 in this study is Swedish. With the research area of cross-linguistic influence in Second Language Acquisition (for an overview, see Jarvis \& Pavlenko 2008; Jarvis 2015) as a departing point, mouth actions are an interesting feature to look at more closely, to provide insights about the role of the L1 on L2 learners' sign language production, especially with regard to the use of mouthing. How has this facilitated their learning? How does it contribute to linguistic accuracy and fluency? In addition, spreading of mouthing is included in the analysis as it may be a kind of idiosyncratic process in all signers, at least in L1 signers (Bank, Crasborn \& van Hout 2015).

The present study looks, for the first time, at mouth actions performed by adult L2 signers, using corpus-based data. This study partly replicates the design of Crasborn et al.s (2008) study, in which the use of mouth actions in L1 signers was investigated and described. Specifically, we describe the distribution of the different mouth actions in STS as L2 and how they are related to L2 signers' proficiency level, as well as how the mouth actions interact with manual signing.

\subsection{The linguistic status of mouth actions in sign languages}

Mouth actions are largely divided into two subcategories: mouth gestures and mouthing (Boyes Braem 2001; see also Crasborn et al. 2008 and Johnston, van Roekel \& Schembri 2016). Mouth gestures are "genuine" mouth movements of sign language. Mouthing, on the other hand, consists of mouth patterns derived from spoken languages based on visual phonetic elements. Thus, mouthing is a 
representation of the spoken word produced with mouth movements, as if silently articulating a word from a spoken language.

Generally, the degree of conventionalization and linguistic status of mouth actions in SLs are subject to discussion in the literature. To date, it has been proposed by some researchers that at least some categories of mouth actions seem to be less linguistically founded than has earlier been thought to be the case, especially categories pertaining to mouth gestures (Johnston, van Roekel \& Schembri 2016). The category of mouthing, however, seems to be more robust linguistically, in that mouthing contributes lexical information, together with the corresponding manual signs. This is of special relevance when there are ambiguous signs involved (in which the difference between signs depends upon contextualization or mouthing): in fact, mouthing has been suggested to be the most conventionalized of all mouth actions identified in SLs so far (Johnston, van Roekel, \& Schembri 2016). The grammatical status of the other category, mouth gestures, however, is still unclear, although some mouth gestures are described as adverbials (Anderson \& Reilly 1998; Brennan 1992; Liddell 1980; Sutton-Spence \& Woll 1999; Lewin \& Schembri 2011; Bank, Crasborn \& van Hout 2016; Johnston, van Roekel \& Schembri 2016). In addition, there are suggestions that mouth actions, specifically mouthing, is not a core component or an integrated part of SL (Ebbinghaus \& Hessmann 2001; Giustolisi, Mereghetti \& Cecchetto 2017). Certainly, however, it is crucial to take into consideration that patterns of mouth actions may differ between different sign languages or as well may reflect usage diversity among the users. In our study, we take STS as our point of departure (cf. Johnston, van Roekel \& Schembri 2016).

In STS, mouth actions have been investigated both in terms of mouth gestures but also with regard to mouthing. Bergman \& Wallin (2003) observed that mouthings are normally used in noun phrases. In another study, Bergman \& Wallin (2001) did a preliminary analysis on the visual segments of mouth gestures compared to mouthings. Their results show that mouthings follow the same native pattern as mouth gestures, that is, mouthing of a Swedish target word with multiple phonemes tends to be reduced to one or two segments such as opening and closing. As such, it follows the same pattern as that observed in mouth gestures.

This mouthing category is called reduced mouthing (see also mouthing in Russian Sign Language, Bauer 2019). In the present study, we refer to it as MEtype, based on Crasborn et al.'s (2008) system, because of the merger of the Mtype and E-type; thus, for example, /styrelse/ 'board' in the M-type is reduced to a single syllable with only one segment /y/ as the ME-type, which resembles the E-type, see Table 1.

Mouth gestures (Boyes Braem \& Sutton-Spence 2001), or so-called multichannel signs (Johnston \& Schembri 2007), have manual and non-manual fea- 
tures which together form a sign with multiple components. This is the case, for example, in the sign KNOW-NOT in STS, which is produced together with a silent bisyllabic mouth articulation (Bergman \& Wallin 2001), and is an example of the E-type. The A-type stands for mouth action types that function as adverbials: different A-type mouth gestures, when combined with manual signs, can modify the meaning of the signs. Thus, in STS, WRITE with the one-segment mouth gesture /ss/ means 'write with effort', and WRITE with /uu/ means 'write easily'. The 4-type and the W-type refer to mouth gestures that are enactments. For instance, the mouth gesture for the action of biting accompanying the sign BITE, i.e., mouth for mouth, is an example of the 4-type. The W-type stands for "whole of face", and here the mouth is part of a whole face expression, as in a prototypical facial expression for "surprise" with open mouth, which, for example, can accompany the manual sign SURPRISE. Finally, the B-type stands for mouth actions related to backchannels by the listener in face-to-face conversation. For example, STS has a specific mouth action, in which the closed lips are protruded repeatedly by the listener, as in kissing somebody, which has the communicative function of a backchannel.

Within the ECHO corpus project (Crasborn et al. 2007; Crasborn et al. 2008) attention was directed to mouth actions. This resulted in the cross-linguistic study of mouth categories in three sign languages, British Sign Language (BSL), Sign Language of the Netherlands (NGT) and Swedish Sign Language (STS). These languages show similar patterns relating to occurrences of mouth gestures (Crasborn et al. 2008). In addition to mouthings, mouth gestures were divided into four subcategories. In Table 1, we present an overview of the existing mouth action categories in STS based on Crasborn et al's categories, and adding MEtype and B-type.

Table 1. Categorization of mouth actions (developed from Crasborn et al. 2008)

\begin{tabular}{lll}
\hline Category & Subcategory & Description \\
\hline \multirow{2}{*}{ Mouthing } & M-type & Mouthing with borrowed elements from Swedish \\
& ME-type & Reduced mouthing based on E-type principles \\
& E-type & Mouth components, i.e., mono- or polysyllabic mouth actions \\
& A-type & Adverbials/adjectival mouth actions \\
Mouth & 4-type & "Mouth for mouth" gestures \\
gestures & W-type & Whole face gestures (i.e., adverbial expression, constructed action, \\
& & congruent, editorial) \\
& B-type & Backchannel. Mouth action as interjection such as smile, lip \\
& & movement forward, repeated \\
\hline
\end{tabular}




\subsection{The status of research on L2 sign languages and mouth actions}

International research on the $\mathrm{L} 2$ acquisition of sign languages is still in a relatively early phase (Mayberry 2006). In the recent literature, it has been referred to as an $\mathrm{L}_{2} \mathrm{M}_{2}$ (or M2L2) learning concept, that is, adding a second modality (M2) aspect to second language (L2) learning as opposed to a more regular unimodal learning situation (L2M1) (e.g., a Dutch speaker learning Swedish as an L2) (Emmorey, Thompson \& Colvin 2009; Ortega \& Morgan 2015a, b, c; Chen Pichler et al. 2016). To date, previous research has focused on articulation/phonological studies regarding the learning of an SL as an L2, specifically with regard to American Sign Language (Mirus, Rathmann \& Meier 2001; Rosen 2004; Bochner et al. 2011), but also, to some extent, British Sign Language (Ortega 2013). Furthermore, some single studies have looked at L2 acquisition of characteristic sign language structures such as depicting signs/classifier constructions (Marshall \& Morgan 2015) and viewpoints of BSL (Gulamani, Marshall \& Morgan 2020), and use of spatial constructions in NTS (Ferrara \& Nilsson 2017). The mouth actions of hearing L2 sign language learners have so far not been studied.

From an L2 perspective, the question of transfer in speech and sign is interesting with respect to the modalities of spoken and signed languages. The study of transfer or cross-linguistic influence in L2 learners forms a vast amount of research within the spoken Second Language Acquisition area. One key point associated with cross-linguistic influence links to linguistic similarity between an L1 and an L2 and transferability (Jarvis 2015; Jarvis \& Pavlenko 2008; Ringbom \& Jarvis 2009). It has also been a subject of interest within sign Second Language Acquisition. Previous research has pointed to limitations in the application of L1 transfer in L2 learning of sign language at least at the phonological level, due to the difference in modality (Ortega \& Morgan 2015a; Bochner et al. 2011). However, recent research has pointed out gestural knowledge as a possible gateway for the transfer to signs. Hearing L2 learners might transfer forms of the same gestures, such as thumbs up and no (palms forward) to their signing for signs with equivalent meaning (Chen Pichler et al. 2016). Gestural knowledge is seen to facilitate L2 signers' comprehension but can contribute to L2 phonological variations in signs, i.e., errors (Ortega \& Morgan 2015b; Ortega, Schiefner \& Özyürek 2019). Ortega, Schiefner \& Özyürek (2019) furthermore suggest that the gestural repertoire serves as manual cognates for learning the sign language lexicon. Studies by Gullberg and colleagues (Gullberg 1998; Gullberg, Bot \& Volterra 2008) have also pointed out the important role of gestures in spoken Second Language Acquisition, among other things, finding a link between language fluency and gesture frequency: that is, gestures are (among other things) used as communica- 
tion strategies to compensate for less language fluency and to overcome obstacles (Gullberg 1998).

In the context of this paper, the category of mouthing is of particular interest. Our view is that the mouth would be a physically possible channel for L1 crosslinguistic influence due to the similarity in mouthing and L2 learners' knowledge of actual pronunciation of spoken words. This could be a factor in their L2 production and a possible source of transferability of patterns from L1 Swedish. As specific mouthings are associated with specific signs, this may facilitate the learners' comprehension and production of signs to some degree. We suspect that this leads to a reliance on or consistent use of mouthing and lexical signs, due to the closeness and similarity to L1 spoken Swedish, which is basically manifested through oral articulation with voicing.

Deaf and hearing signers frequently use mouthing (with or without voicing) and signing simultaneously. Here a bilingual perspective should also be added. Mouthing in this sense, i.e., manual signing being used with mouthing/voicing of words simultaneously, is generally considered to be a result of code-blending that is commonly observed in bimodal bilinguals, who are basically fluent in both languages (Emmorey et al. 2008). However, in this context, from an L2 perspective, hearing sign language learners do have language knowledge in spoken language, e.g., Swedish, and mouthing in STS is a part of language contact with Swedish, but due to their limited fluency in STS and the degree of perceived similarity between Swedish and STS with regard to the component mouthing, we propose that crosslinguistic influence is the key issue here rather than a bilingual effect.

Here we could compare with a mouthing study of L1 signers of Hungarian Sign Language, in which L2 signers were described as non-fluent signers due to their use of "continuous" mouthing (Racz-Engelhardt 2016). Generally speaking, the use of mouth actions is frequently discussed in the Swedish deaf signing community. Often the degree of use of mouthing is used as a measurement of sign language proficiency. At the same time, we don't know how L2 signers acquire different mouth categories. Further, no previous study has investigated the learning of mouth actions by hearing L2 students in STS. A small study was performed, however, in the context of Swiss German Sign language (Boyes Braem 2001), where it was found that the mouth action patterns of deaf late signers were different from those of deaf early learners, i.e., the amount of mouthing was higher for late signers.

Finally, a better understanding of the mouth action patterns in hearing L2 signers may help us to gain new insights about the use in the L1 group, too, in order to contribute to our understanding of linguistic diversity. 


\subsection{The present study}

By means of a Swedish Sign Language as an L2 Corpus, the present study will describe the acquisition and use of mouth actions of $\mathrm{L}_{2}$ learners of STS. The corpus is longitudinal, which enables us to track the acquisition of mouth actions among the L2 learners. This study adopts a descriptive nature, in which we examine group and individual variation in the use of mouth actions between the learner groups as well as the control L1 group. Furthermore, we will describe use of the spreading of mouth actions among the groups. Finally, we look at which mouth actions are used together with grammatical class of the associated signs.

\section{Data and method}

Data from a learner's corpus in STS, Corpus in Swedish Sign Language as a second language STSC-L2 (Schönström \& Mesch 2017), are used in this study. The corpus itself consists of a dataset with longitudinal data collected from 38 adult hearing L2 learners of STS. Data were collected on four occasions during a time period of 16 months (September Year 1 - December Year 2). The total data set of the L2 corpus consists of approximately 25:06 hours, of which $71 \%$ has been annotated so far, consisting of 38,287 gloss tokens of signing by 38 L2 learners. In addition, the control corpus consists of 1:22 hours of data of which $80 \%$ is annotated so far, consisting of 2,445 glossed tokens of signing by nine deaf $\mathrm{L} 1$ signers. For a detailed account of the design and collection of the STSC-L2, see Mesch \& Schönström (2018).

For this study, data from two types of sessions from the corpus were selected: Interviews (in total 1:49:55 hours for occasion 2 and 1:59:43 hours for occasion 4) and retellings of a movie clip from "The Plank" (in total 45:10 minutes for occasion 2 and 22:32 minutes for occasion 4 ).

The interview part of the data is a dialogue where the participants were asked to engage in a short conversation with an L1 user of STS, around topics including personal information, daily life, and work. The questions initiated by the $\mathrm{L}_{1}$ interviewer have been created in the framework of the level descriptors of the Common European Framework of Reference for Languages (CEFR) ${ }^{1}$ (Council of Europe 2001). That is, the interview questions were formulated according to students' expected CEFR proficiency level - A1 (beginner), A2 (beginner plus), B1

1. CEFR levels $\mathrm{A}_{1}-\mathrm{A}_{2}$ correspond to beginner level, $\mathrm{B}_{1}-\mathrm{B}_{2}$ to intermediate level, and $\mathrm{C}_{1}-\mathrm{C}_{2}$ to advanced level; see: https://www.coe.int/en/web/common-european-framework-referencelanguages/level-descriptions. 
(intermediate), up to $\mathrm{B}_{2}$ level (intermediate plus) - at the recording occasion. The goal is to identify a baseline for communicative competence. Some questions in STS for the first recording (according to level A1) looked like this: Hello, what is your name? Where do you live? What do you do/what do you work with? What are your interests? Why are you studying sign language? How did you get in contact with sign language for the first time? Do you know anybody who is deaf? For the last recording, open conversations about more complex topics according to level $\mathrm{B}_{2}$ of CEFR were added in addition to previous questions. The questions were more open, and there were follow-up questions. For example, topics about climate change and student accommodation were discussed.

In the retelling part, participants were asked to retell a short narrative from a selected one-minute clip of the British short movie "The Plank". The sequence includes two men trying to handle a plank which they are moving through different obstacles in a city.

Both parts provide variation in language use through two different kinds of textual data, one narrative and one dialogue. While the narrative is controlled in content, the interview dialogue is more open. Thus, we can compare the learners across different kinds of data and obtain a broader coverage of their linguistic competence.

\subsection{Participants}

Participants are first- and second-year university students from a sign language and interpreting program. For this study, sampled corpus data with up to 16 individuals from the second ( $\left.\mathrm{L}_{2}-\mathrm{T}_{2}\right)$ and the fourth $\left(\mathrm{L}_{2}-\mathrm{T}_{4}\right)$ occasions of data collection were analyzed. None of the participants had any experience in sign language before starting studying sign language at university level. Two of them are male. Sixteen individuals (Mean age 23.6, range 19-28) from occasion 2 and from occasion 4 are selected for this study. A control group of native/near-native nine deaf L1 signers (mean age 27.6, range 20-50) is also added for this study.

Due to the dynamic progress of university students, with patterns of quitting and returning to their program, we adopt a cross-sectional comparison of the groups in order to maximize the number of students for each group. It should be noted that the groups' number is uneven $\mathrm{L}_{2}-\mathrm{T}_{2}(n=15)$ and $\mathrm{L}_{2}-\mathrm{T}_{4}(n=10)$, see Table 2. 
Table 2. Informants participating in the retellings and interviews

\begin{tabular}{|c|c|c|c|c|c|c|}
\hline $\begin{array}{l}\text { L2 } \\
\text { group }\end{array}$ & Age & Sex & $\begin{array}{l}\text { Session } \\
\text { time }\end{array}$ & $\begin{array}{l}\text { Length } \\
\text { (hh:mm:ss) }\end{array}$ & $\begin{array}{l}\text { Session } \\
\text { time }\end{array}$ & $\begin{array}{l}\text { Length } \\
\text { (hh:mm:ss) }\end{array}$ \\
\hline So54 & 27 & $\mathrm{~F}$ & $\mathrm{~T} 2$ & $00: 09: 34$ & & \\
\hline So55 & 24 & $\mathrm{~F}$ & $\mathrm{~T} 2$ & oo:09:49 & & \\
\hline So57 & 19 & $\mathrm{~F}$ & & & $\mathrm{~T}_{4}$ & $00: 12: 03$ \\
\hline So 58 & 22 & $\mathrm{~F}$ & $\mathrm{~T} 2$ & $00: 08: 54$ & $\mathrm{~T}_{4}$ & 00:18:09 \\
\hline So59 & 19 & $\mathrm{~F}$ & $\mathrm{~T} 2$ & 0o:08:19 & $\mathrm{T}_{4}$ & $00: 15: 27$ \\
\hline So6o & 40 & $\mathrm{~F}$ & $\mathrm{~T} 2$ & $00: 07: 03$ & & \\
\hline So61 & 23 & $\mathrm{~F}$ & $\mathrm{~T} 2$ & $00: 09: 46$ & $\mathrm{~T}_{4}$ & $00: 20: 07$ \\
\hline So95 & 23 & $\mathrm{~F}$ & $\mathrm{~T} 2$ & $00: 11: 05$ & & \\
\hline Sog6 & 19 & $\mathrm{~F}$ & $\mathrm{~T}_{2}$ & $00: 11: 35$ & $\mathrm{~T}_{4}$ & $00: 16: 59$ \\
\hline So97 & 24 & $\mathrm{~F}$ & $\mathrm{~T} 2$ & $00: 06: 30$ & $\mathrm{~T}_{4}$ & $00: 11: 27$ \\
\hline S100 & 22 & $\mathrm{~F}$ & $\mathrm{~T}_{2}$ & $00: 10: 27$ & $\mathrm{~T}_{4}$ & $00: 14: 24$ \\
\hline S111 & 22 & M & $\mathrm{T} 2$ & $00: 09: 16$ & $\mathrm{~T}_{4}$ & $00: 06: 12$ \\
\hline $\mathrm{S}_{113}$ & 21 & M & $\mathrm{T} 2$ & $00: 11: 18$ & & \\
\hline$S_{114}$ & 20 & $\mathrm{~F}$ & $\mathrm{~T} 2$ & $00: 15: 31$ & & \\
\hline$S_{115}$ & 24 & $\mathrm{~F}$ & $\mathrm{~T} 2$ & $00: 13: 47$ & $\mathrm{~T}_{4}$ & oo:13:31 \\
\hline$S_{116}$ & 28 & $\mathrm{~F}$ & $\mathrm{~T} 2$ & $00: 12: 11$ & $\mathrm{~T}_{4}$ & $00: 13: 56$ \\
\hline Total & & & & $2: 35: 05$ & & $2: 22: 15$ \\
\hline $\begin{array}{l}\text { L1 } \\
\text { group }\end{array}$ & Age & Sex & & & & $\begin{array}{l}\text { Length } \\
\text { (hh:mm:ss) }\end{array}$ \\
\hline So68 & 50 & $\mathrm{~F}$ & & & & 00:08:01 \\
\hline So69 & 21 & M & & & & $00: 07: 25$ \\
\hline So7o & 44 & $\mathrm{~F}$ & & & & $00: 07: 01$ \\
\hline $\mathrm{S}_{103}$ & 21 & $\mathrm{~F}$ & & & & $00: 04: 15$ \\
\hline $\mathrm{S}_{104}$ & 23 & $\mathrm{~F}$ & & & & oo:06:16 \\
\hline$S_{105}$ & 20 & $\mathrm{~F}$ & & & & $00: 03: 29$ \\
\hline S106 & 24 & $\mathrm{~F}$ & & & & $00: 04: 32$ \\
\hline $\mathrm{S}_{107}$ & 21 & $\mathrm{~F}$ & & & & $00: 05: 31$ \\
\hline $\mathrm{S}_{108}$ & 24 & $\mathrm{~F}$ & & & & $00: 04: 27$ \\
\hline Total & & & & & & $0: 50: 57$ \\
\hline
\end{tabular}

\subsection{Coding and analysis}

All selected data are annotated with sign glosses in the tiers "Gloss_DH" (dominant hand manual signing) and "Gloss_NonDH" (non-dominant hand manual signing when it is independent, not parallel for two-handed signs) following the 
annotation conventions for STS (Mesch \& Wallin 2015; Wallin \& Mesch 2018). The translation tiers are also added.

For this analysis, as a first step, the tier "Mouth categories" is added. The annotation tags for mouth categories are based on and developed from Crasborn et al. (2008) as described in Table 1 above. However, some tags were developed during the annotation work of the STSC-L2 corpus: (i) the tag "ME-type" is added deliberately to show that L1 signers use reduced mouthing at a higher rate than L2 signers; (ii) the tag "no action" is added for the neutral mouth movement or no movement; (iii) indefinite or unidentifiable mouth actions were tagged as indefinite; and (iv) B-type, backchanneling mouth action, i.e., a backchannel marker, used mostly in interviews, is included in the analysis. Furthermore, we observed examples of mouth actions without accompanying manual signs, so we added tags in the gloss tier in order to show that mouthing can be used without any manual sign, for instance "m-type:och" [m-type:and] in the gloss tier. The annotations of mouthings were double-checked by two deaf researchers fluent in STS.

Additionally, two tags for regressive and progressive spreading of (each category of ) mouth actions were added for further analysis (Table 3). This means that the mouth actions may spread regressively to the previous manual sign or progressively to the following manual sign. The tags used here are limited in comparison to the tags used in Bank et al's study on spreading subcategories (Bank, Crasborn \& van Hout 2015).

Table 3. The tags for spreading of mouth action

\begin{tabular}{ll}
\hline Tag & Description \\
\hline M/E/A-type.progr & Progressive spreading of mouth action \\
M/E/A-type.regr & Regressive spreading of mouth action \\
\hline
\end{tabular}

Grammatical class (part of speech) tags are attached to the sign gloss annotations on the sign gloss tier (e.g., "DANCE[NN/VB]") (Börstell et al. 2016). Some glosses, e.g., DANCE 'dance' have no formal distinction between noun-verb, and the tag can be changed from NN to VB if necessary. The tagging is mostly influenced by the semantics of its use. Then, mouth actions can be analyzed in relation to grammatical class for sign glosses. 


\section{Results}

\subsection{Distribution of mouth actions}

The proportion of mouth actions is studied in two discourse types (retellings and interviews) used by the learner groups $\mathrm{L}_{2}-\mathrm{T}_{2}$ and $\mathrm{L}_{2}-\mathrm{T}_{4}$ in comparison with the L1 group. Table 4 shows distribution and number of manual signs (DH and NonDH glosses) and mouth actions per group. Overall, both L2 groups use mouth actions in higher proportion to signs in comparison to the L1 group in all cases. L2 groups maintain a consistent ratio after 1 year of teaching. Notable is that the L2 groups as well as the L1 group use mouth actions more in interviews in comparison with the retelling data.

Table 4. Number and ratio of manual signs $(G)$ and mouth actions (M) in three groups and two discourse types ( $\mathrm{N}$ total)

\begin{tabular}{lccc}
\hline & $N$ Gloss & N Mouth actions & Ratio (G:M) \\
\hline Retelling L2-T2 & 1567 & 1095 & $1: 0.70$ \\
Retelling L2-T4 & 1240 & 867 & $1: 0.70$ \\
Retelling L1 & 1314 & 660 & $1: 0.50$ \\
Interview L2-T2 & 3261 & 2801 & $1: 0.86$ \\
Interview L2-T4 & 6134 & 5204 & $1: 0.85$ \\
Interview L1 & 3288 & 2348 & $1: 0.71$ \\
\hline
\end{tabular}

Number and percentages of total mouth actions for each participating group and all discourse types are shown in Table 5. As can be seen, the M-types are the most common category in all groups. Proportionally, it is the most used category within the $\mathrm{L}_{2}$ group, with $81.3 \%$ of use in $\mathrm{L}_{2}-\mathrm{T}_{2}(n=15)$ and $82.5 \%$ in $\mathrm{L}_{2}-\mathrm{T}_{4}$ group $(n=10)$ compared to the L1 group with $42.3 \%$ use of the M-type. The L1 group use a variant of reduced mouthing, i.e., the ME-type (20.2\%). In Table 5, we also took note of the use of indefinite mouth actions as well as no use of mouth action. The number of indefinite forms appears in both learner groups at a higher rate compared to the L1 group, in particular for the L2-T2 group. This seems to decrease with time, that is, articulation gets better with time. Also notable is the use of no mouth action: it forms a considerable part of the L1 group, with a proportion of 26.8\%; see Table 5. We can notice an increased amount of no action in $\mathrm{L}_{2}-\mathrm{T}_{4} \mathrm{com}$ pared to L2-T2. The other mouth categories appear in smaller numbers. The Atypes and E-types are frequently used in L1 compared to $\mathrm{L}_{2}$ on all occasions. It should be noted that the learners in $\mathrm{T}_{4}$ are approaching the pattern of that of $\mathrm{L}_{1}$ users, that is, they display a decline in the M-type as well as an increased amount 
of No action and other mouth categories. L2 learners use the W-type to a greater extent compared to L1 signers. This is interesting: one possible explanation would be (over) use of a gesture strategy in order to compensate for obstacles in language production.

Table 5. Number and percentage of mouth actions including indefinite and no mouth action (retellings and interviews)

\begin{tabular}{lrrrrrr}
\hline & & $\begin{array}{c}\text { L2-T2 } \\
(n=15)\end{array}$ & & $\begin{array}{c}\text { L2-T4 } \\
(n=10)\end{array}$ & & $\begin{array}{c}\text { L1 } \\
(n=9)\end{array}$ \\
\hline M-type & 3,667 & $80.7 \%$ & 5,717 & $81.9 \%$ & 1,755 & $42.3 \%$ \\
ME-type & 28 & $0.6 \%$ & 24 & $0.3 \%$ & 837 & $20.2 \%$ \\
E-type & 27 & $0.6 \%$ & 98 & $1.4 \%$ & 202 & $4.9 \%$ \\
A-type & 27 & $0.6 \%$ & 100 & $1.4 \%$ & 136 & $3.3 \%$ \\
W-type & 90 & $2.0 \%$ & 110 & $1.6 \%$ & 40 & $1.0 \%$ \\
B-type & 54 & $1.2 \%$ & 16 & $0.2 \%$ & 35 & $0.8 \%$ \\
4-type & 3 & $0.1 \%$ & 6 & $0.1 \%$ & 3 & $0.1 \%$ \\
Indefinite & 303 & $6.7 \%$ & 250 & $3.6 \%$ & 34 & $0.8 \%$ \\
No action & 346 & $7.6 \%$ & 657 & $9.4 \%$ & 1,112 & $26.8 \%$ \\
Total & 4,545 & $\mathbf{1 0 0 \%}$ & $\mathbf{6 , 9 7 8}$ & $\mathbf{1 0 0 \%}$ & $\mathbf{4 , 1 5 4}$ & $\mathbf{1 0 0 \%}$ \\
\hline
\end{tabular}

Table 6 shows the mean use of mouth categories per person. A chi-square test showed that the relation between group mean and mouth output was significant, $X^{2}(16)=377.6, p<.000$, that is, there is a difference between the groups in their use of mouth actions. Overall, $\mathrm{L}_{2}-\mathrm{T}_{4}$ signers produce longer utterances compared to both L2-T2 signers and L1 signers, which is noted in mean total use.

Table 6. Mean quantity mouth actions per person

\begin{tabular}{lrrr}
\hline & $\begin{array}{r}\text { L2-T2 } \\
(n=15)\end{array}$ & $\begin{array}{c}\text { L2-T4 } \\
(n=10)\end{array}$ & $\begin{array}{c}\text { L1 } \\
(n=9)\end{array}$ \\
\hline M-type & 244.5 & 571.7 & 195.0 \\
ME-type & 1.9 & 2.4 & 93.0 \\
E-type & 1.8 & 9.8 & 22.4 \\
A-type & 1.8 & 10.0 & 15.1 \\
W-type & 6.0 & 11.0 & 4.4 \\
B-type & 3.6 & 1.6 & 3.9 \\
4-type & 0.2 & 0.6 & 0.3 \\
Indefinite & 20.2 & 25.0 & 3.8 \\
No action & 23.1 & 65.7 & 123.6 \\
Total & $\mathbf{3 0 3 . 0}$ & $\mathbf{6 9 7 . 8}$ & $\mathbf{4 6 1 . 6}$ \\
\hline
\end{tabular}


3.2 Distribution of mouth actions by L2 learners and L1 signers - discourse types

Table 7 shows the proportions of mouth actions in retellings and interviews. The L2 groups clearly use the M-type more than the L1 group, especially in the interview data. In interviews, a higher proportion of the M-type is expected, due to the nominal characteristics of the content, i.e., its discourse; we see this pattern as well for the control group. The L1 signers use reduced mouthings (ME-type), too, which is rarely seen in the L2 groups. Between L2 and L1 we can see that the E-type and the A-type are more commonly used within the L1 group, but their use differs depending on discourse type. Syllabic mouth actions (E-type) are frequently used in the L1 group, especially in interviews (7.6\%) compared to L2 groups even if there is a slight increase in the L2-T4 group. Next, the A-type is frequently used by the L1 group in retellings (13.5\%), whereas L2 signers seem to increase the use of the A-type with time. In retellings, the $\mathrm{W}$-type is a prominent category as well, with $7.2 \%$ for $\mathrm{L}_{2}-\mathrm{T}_{2}, 6.8 \%$ for $\mathrm{L}_{2}-\mathrm{T}_{4}$, and $4.7 \%$ for $\mathrm{L}_{1}$ group. The $\mathrm{W}$-type, gestural mouth actions integrated with face, could have been triggered due to the nature of elicited data which include several roles, contributing to L2 signers using their gestural knowledge. No bigger difference between L2-T2 and $\mathrm{L}_{2}-\mathrm{T}_{4}$ could be detected apart from use of the B-type.

As expected, patterns in the use of mouth actions differ depending on discourse type in L2 signers and L1 signers. L1 signers use a more varied palette of mouth actions in retellings compared to the interview data.

Table 7. Number and percentage of mouth actions of each mouth category in retellings (totals for each participant group)

\begin{tabular}{|c|c|c|c|c|c|c|c|c|c|c|c|c|}
\hline & \multicolumn{4}{|c|}{$\mathrm{L}_{2}-\mathrm{T}_{2}$} & \multicolumn{4}{|c|}{$\mathrm{L}_{2}-\mathrm{T}_{4}$} & \multicolumn{4}{|c|}{ L1 } \\
\hline & \multicolumn{2}{|c|}{ Retellings } & \multicolumn{2}{|c|}{ Interviews } & \multicolumn{2}{|c|}{ Retellings } & \multicolumn{2}{|c|}{ Interviews } & \multicolumn{2}{|c|}{ Retellings } & \multicolumn{2}{|c|}{ Interviews } \\
\hline M-type & 979 & $89.4 \%$ & 2688 & $96.0 \%$ & 720 & $83.0 \%$ & 4997 & $96.0 \%$ & 245 & $37.1 \%$ & 1510 & $64.3 \%$ \\
\hline $\begin{array}{l}\text { ME- } \\
\text { type }\end{array}$ & 11 & $1.0 \%$ & 17 & $0.6 \%$ & 16 & $1.8 \%$ & 8 & $0.2 \%$ & 264 & $40.0 \%$ & 573 & $24.4 \%$ \\
\hline E-type & 6 & $0.5 \%$ & 21 & $0.7 \%$ & 13 & $1.5 \%$ & 85 & $1.6 \%$ & 24 & $3.6 \%$ & 178 & $7.6 \%$ \\
\hline A-type & 16 & $1.5 \%$ & 11 & $0.4 \%$ & 53 & $6.1 \%$ & 47 & $0.9 \%$ & 89 & $13.5 \%$ & 47 & $2.0 \%$ \\
\hline W-type & 79 & $7.2 \%$ & 11 & $0.4 \%$ & 59 & $6.8 \%$ & 51 & $1.0 \%$ & 31 & $4.7 \%$ & 9 & $0.4 \%$ \\
\hline B-type & 2 & $0.2 \%$ & 52 & $1.9 \%$ & 2 & $0.2 \%$ & 14 & $0.3 \%$ & 5 & $0.8 \%$ & 30 & $1.3 \%$ \\
\hline 4-type & 2 & $0.2 \%$ & 1 & $0.0 \%$ & 4 & $0.5 \%$ & 2 & $0.0 \%$ & 2 & $0.3 \%$ & 1 & $0.0 \%$ \\
\hline Total & 1095 & & 2801 & & 867 & & 5204 & & 660 & & 2348 & \\
\hline
\end{tabular}


3.3 Individual variation in the frequency and distribution of mouth actions

In Figures 1 and 2, the individual variation in the use of mouth actions of $\mathrm{L}_{2}-\mathrm{T}_{2}$ and $\mathrm{L}_{2}-\mathrm{T}_{4}$ learners (in retellings and interviews) is summarized. As expected, the quantity of mouth actions used is idiosyncratic both in L2 groups as well as in the L1 group (Figure 3). With regard to proportion of mouth categories used, it can be noted that there is a greater variability within the $\mathrm{L}_{2}$ groups compared to the $\mathrm{L}_{1}$ group, which is more constant across the users, with some exceptions.

Most mouthings (M-type) appear to be fully articulated, ranging between $71.3 \%$ and $90.7 \%$ in the $\mathrm{L}_{2}-\mathrm{T}_{2}$ group and between $73.9 \%$ and $92.8 \%$ in the $\mathrm{L}_{2}-\mathrm{T}_{4}$ group. Reduced mouthings (ME-type) are less represented in both groups. MEtype rates range from nothing to a high of $2.4 \%$ in the $\mathrm{L}_{2}-\mathrm{T}_{2}$ and $0.9 \%$ in the $\mathrm{L} 2-\mathrm{T}_{4}$. One common pattern is that the ME-type is used very infrequently across the learners. By contrast, the M-type is very frequent for some learners across time, for example So61, whose use of the M-type represents over $90 \%$ of the mouth actions at $\mathrm{T}_{2}$ and $\mathrm{T}_{4}$. Some learners, for example So97, seem to decline in the use of M-type from $94.2 \%$ to $85.7 \%$.

Incomplete mouthings are clearly represented, but vary individually. But the range seems to decrease with proficiency for the Indefinite type. While in the L2-T2 learners, rates for the Indefinite type ranged from a low of $2.3 \%$ to a high of $20.5 \%$, in the $\mathrm{L}_{2}-\mathrm{T}_{4}$ learners (no action), rates for the Indefinite type ranged from a low of $1.2 \%$ to a high of $8.9 \%$. The number range of no action type seems to be relatively consistent through $\mathrm{L}_{2}-\mathrm{T}_{2}$ and $\mathrm{L}_{2}-\mathrm{T}_{4}$ with $0.0 \%$ to $19.0 \%$ and $1.0 \%$ to $18.8 \%$, respectively. Interestingly, for $\mathrm{L}_{2}-\mathrm{T}_{4}$, there are individual differences in the A-type compared to L2-T2. It seems that use of the A-type increases in some of the learners but not all.

Overall, there is a tendency for L1 signers to use mouth actions compared to signs less frequently, see Figure 3. Another observation is that mouth actions among L1 signers are more consistently variable, especially with regard to the fact that L1 signers do not always use mouth actions at all: in fact, no use of mouth action is relatively constant. The greatest individual variation found is associated with the M-type and the ME-type: together they are constant but there is individual variation in the distribution of the M- and ME-types. ME-type rates ranged from a low of $10.4 \%$ to a high of $32.4 \%$.

\subsection{Spreading of mouth actions}

As mentioned above, two mouth action types, the M-type (mouthings) and the E-type (semantically empty mouth gestures), are lexically associated. The A-type are conventional adverbials that function as a modifier to the co-occurring man- 


\section{$\mathrm{L} 2$ - $\mathrm{T} 2$ retellings and interviews}

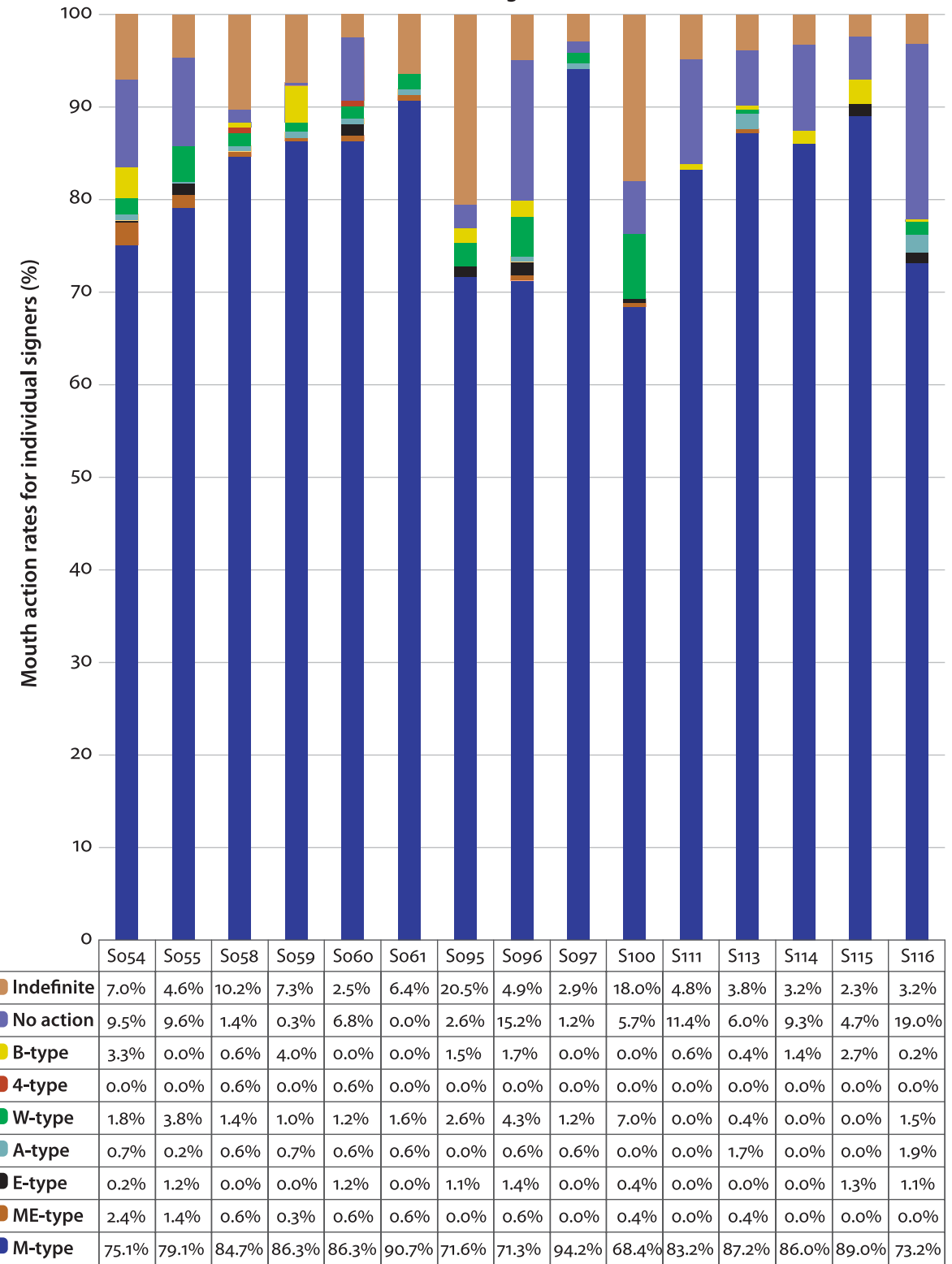

Figure 1. Individual variation in the frequency of occurrence of mouth actions in L2-T2 signers in retellings and interviews

ual sign. In signing, these mouth actions are able to spread regressively (leftward) or progressively (rightward), so they create a prosodic binding. These spreadings 


\section{$\mathrm{L} 2$ - $\mathrm{T} 4$ retellings and interviews}

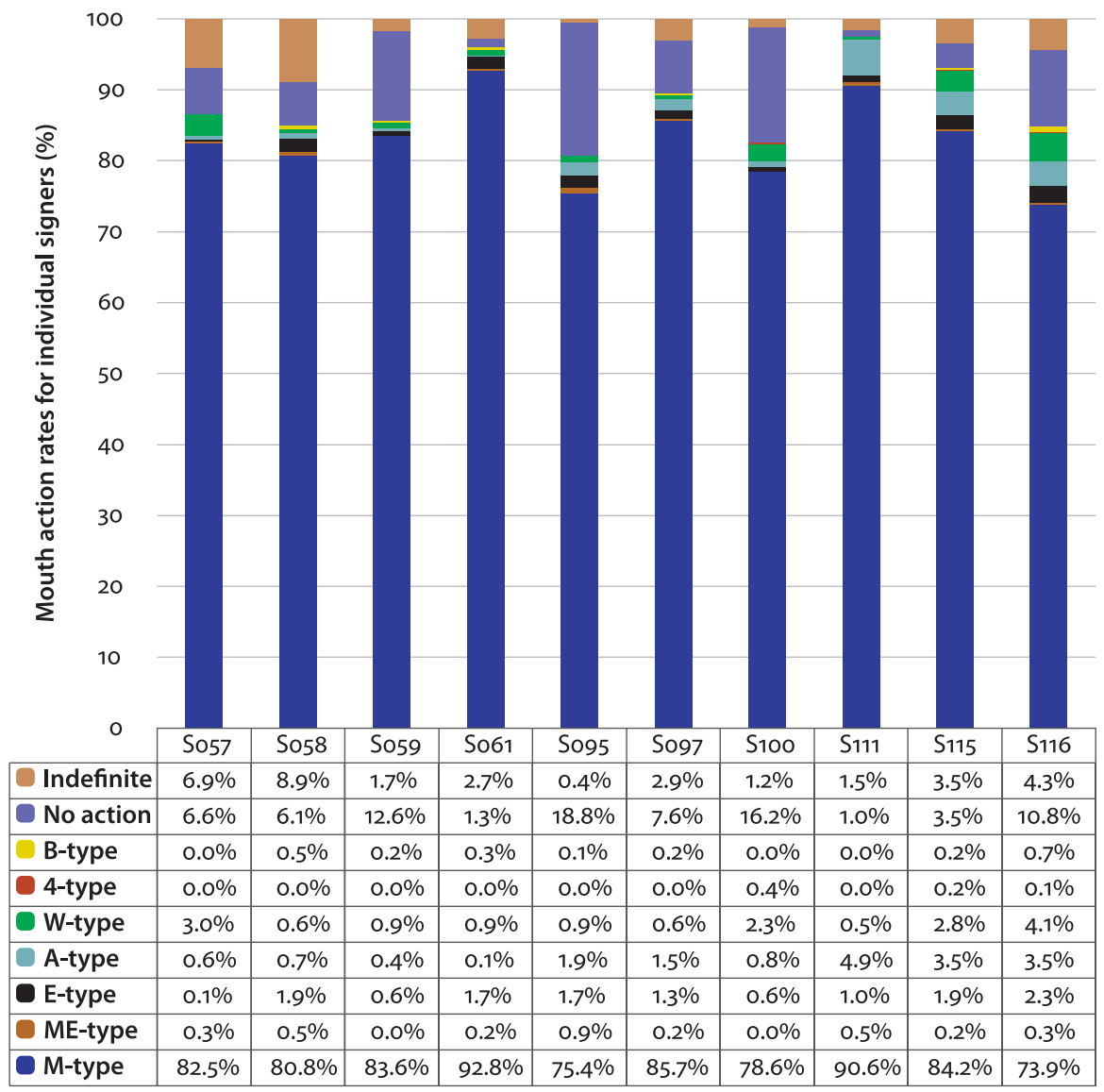

Figure 2. Individual variation in the frequency of occurrence of mouth actions in $\mathrm{L}_{2}-\mathrm{T}_{4}$ signers in retellings and interviews

in sign language production are common but can vary individually among signers (Bank, Crasborn \& van Hout 2015).

Our data show that L2 learners may have difficulty in coordinating manual articulators and mouth actions. During their sign language learning, they seem to change their "way" from formulating mouthing (M-type) parallel with manual signs to signing with closed lips (no action), and then back to using the M-type. This leads to a large number of disfluencies in signing.

Spreading behavior in mouthings is clearly more commonly present in the L1 group in comparison with the L2 groups. Mouth actions may either spread leftward (progressive) or rightward (regressive). It is not typical for the A-type to 
L1 retellings and interviews

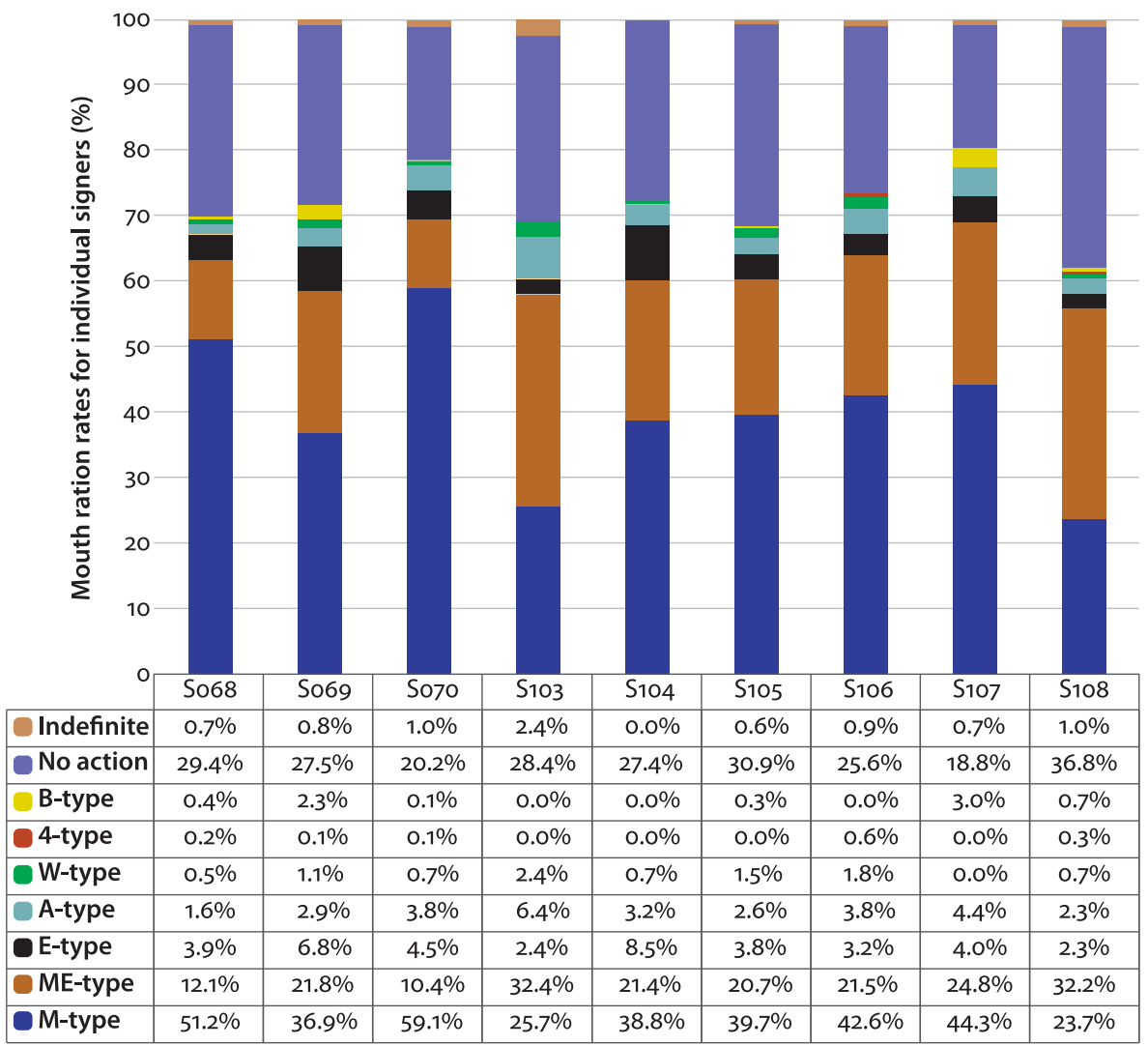

Figure 3. Individual variation in the frequency of occurrence of mouth actions of $\mathrm{L}_{1}$ in retellings and interviews

undergo spreading. Only two instances of spreading are found in the A-type of one $\mathrm{L}_{1}$ signer. In the retellings, $\mathrm{L}_{2}$ learners seem to have not learned yet to sign fluently compared to L1 signers, who show a high proportion of spreading in the M-type, see Table 8 . The most common spreading type with mouthings is the progressive type. Interestingly, learners tend to develop their spreading behavior in both retellings and interviews, approaching the pattern of the target language. Still, none of the learners show any spreading behavior in the ME-type.

\subsection{Grammatical class}

Earlier studies, including studies on STS, have suggested that mouthing appears with nouns or noun phrases, "uninflected" verb forms, open-class items, and 
Table 8. Distribution of progressive and regressive spreading

\begin{tabular}{|c|c|c|c|c|c|c|}
\hline \multirow[t]{2}{*}{ Spreading (token) } & \multicolumn{3}{|c|}{ Retellings } & \multicolumn{3}{|c|}{ Interviews } \\
\hline & $\mathrm{L}_{2}-\mathrm{T} 2$ & $\mathrm{~L}_{2}-\mathrm{T}_{4}$ & $\mathrm{~L}_{1}$ & $\mathrm{~L}_{2}-\mathrm{T}_{2}$ & $\mathrm{~L}_{2}-\mathrm{T}_{4}$ & $\mathrm{~L}_{1}$ \\
\hline A-type.progr & o & o & o & o & o & 1 \\
\hline A-type.regr & o & o & o & o & o & 1 \\
\hline M-type.progr & 2 & 13 & 22 & 3 & 14 & 33 \\
\hline M-type.regr & 1 & 4 & 1 & o & 3 & 18 \\
\hline ME-type.progr & o & o & 3 & o & o & 7 \\
\hline ME-type.regr & o & o & 1 & o & o & 0 \\
\hline
\end{tabular}

"morphologically simple" signs (Bergman \& Wallin 2001; Crasborn et al. 2008; Lewin \& Schembri 2011). Given this background, and since STSC-L2 includes annotations for grammatical class, we present some frequency and distribution data for this analysis based on those mouthings which are used most frequently (i.e., M-type, ME-type). In addition, we think adverbial mouth gestures (A-type) are interesting given their class, so we have added them here as well, despite their low frequency. The results are presented in Table 9. It should be noted that not all grammatical classes that are part of the STSC annotation system are included and listed in the table, that is, specific ones such as interjections, noun classifiers, and buoys are excluded. Here, we focus on traditional parts of speech categories.

Our results confirm earlier findings (Bergman \& Wallin 2001; Crasborn et al. 2008) that mouthing (M-type) is most common with noun signs as well as lexical verb signs (and not depicting signs) among L1 signers. It also appears frequently with adverb signs. Overall, the differences between L1 and L2 signers are not striking; the distribution of mouth categories according to grammatical class is similar across the groups. However, there are some quantitative differences related to groups. The M-type is more frequent in verbs in the L2 groups as compared to the L1 group. The M-type also tends to be more frequently used for nouns $(32.2 \%$ in $\mathrm{L}_{2}-\mathrm{T}_{2}, 25.2 \%$ in L2-T4, and $38.4 \%$ for L1 signers).

As the frequency of the ME-type is small in the L2 groups, it is difficult to draw conclusions. However, the data reveal that L1 signers produce the ME-type with all grammatical classes, mostly with nouns, verbs, and adverbs. Compared to the M-type, the ME-type is more often used with verbs and adverbs compared to nouns. This corresponds to the results regarding distribution of mouth categories (see Section 3.1), that is, the M-type is more frequently used by L2 signers, which affects how they are used across grammatical class.

As the A-type is less frequently used overall, it is hard to draw definitive conclusions. However, we see that there is no significant difference in the distribution of the A-type according to a sign's grammatical class in all groups. The A-type is 
Table 9. Number and percentages of M/ME/A-type mouthing according to grammatical class (retellings and interviews)

\begin{tabular}{|c|c|c|c|c|c|c|}
\hline M-type & $\mathrm{L}_{2}-\mathrm{T}_{2}$ & & $\mathrm{~L}_{2}-\mathrm{T}_{4}$ & & L1 & \\
\hline Adverb & 401 & $12.5 \%$ & 828 & $16.0 \%$ & 198 & $12.2 \%$ \\
\hline Adjective & 199 & $6.2 \%$ & 347 & $6.7 \%$ & 119 & $7.3 \%$ \\
\hline Conjunction & 112 & $3.5 \%$ & 400 & $7.7 \%$ & 67 & $4.1 \%$ \\
\hline Noun & 1036 & $32.2 \%$ & 1301 & $25.2 \%$ & 622 & $38.4 \%$ \\
\hline Numeral & 131 & $4.1 \%$ & 140 & $2.7 \%$ & 79 & $4.9 \%$ \\
\hline Preposition & 192 & $6.0 \%$ & 258 & $5.0 \%$ & 85 & $5.2 \%$ \\
\hline Pronoun & 396 & $12.3 \%$ & 626 & $12.1 \%$ & 162 & $10.0 \%$ \\
\hline Verb & 709 & $22.1 \%$ & 1236 & $23.9 \%$ & 284 & $17.5 \%$ \\
\hline Depicting Sign & 39 & $1.2 \%$ & 34 & $0.7 \%$ & 4 & $0.2 \%$ \\
\hline Total & 3215 & $100.0 \%$ & 5170 & $100.0 \%$ & 1620 & $100.0 \%$ \\
\hline ME-type & $\mathrm{L}_{2}-\mathrm{T}_{2}$ & & $\mathrm{~L}_{2}-\mathrm{T}_{4}$ & & L1 & \\
\hline Adverb & 2 & $9.1 \%$ & 3 & $14.3 \%$ & 186 & $24.3 \%$ \\
\hline Adjective & 4 & $18.2 \%$ & o & $0.0 \%$ & 52 & $6.8 \%$ \\
\hline Conjunction & o & $0.0 \%$ & 1 & $4.8 \%$ & 38 & $5.0 \%$ \\
\hline Noun & 5 & $22.7 \%$ & 9 & $42.9 \%$ & 116 & $15.2 \%$ \\
\hline Numeral & 0 & $0.0 \%$ & 0 & $0.0 \%$ & 13 & $1.7 \%$ \\
\hline Preposition & o & $0.0 \%$ & 3 & $14.3 \%$ & 27 & $3.5 \%$ \\
\hline Pronoun & o & $0.0 \%$ & 0 & $0.0 \%$ & 44 & $5.8 \%$ \\
\hline Verb & 11 & $50.0 \%$ & 4 & $19.0 \%$ & 280 & $36.6 \%$ \\
\hline Depicting Sign & o & $0.0 \%$ & 1 & $4.8 \%$ & 8 & $1.0 \%$ \\
\hline Total & 22 & $100.0 \%$ & 21 & $100.0 \%$ & 764 & $100.0 \%$ \\
\hline A-type & $\mathrm{L}_{2}-\mathrm{T}_{2}$ & & $\mathrm{~L}_{2}-\mathrm{T}_{4}$ & & $\mathrm{~L}_{1}$ & \\
\hline Adverb & o & $0.0 \%$ & 6 & $6.5 \%$ & 2 & $1.7 \%$ \\
\hline Adjective & 4 & $16.0 \%$ & 5 & $5.4 \%$ & 5 & $4.2 \%$ \\
\hline Conjunction & o & $0.0 \%$ & o & $0.0 \%$ & o & $0.0 \%$ \\
\hline Noun & 1 & $4.0 \%$ & 2 & $2.2 \%$ & 4 & $3.4 \%$ \\
\hline Numeral & o & $0.0 \%$ & o & $0.0 \%$ & 0 & $0.0 \%$ \\
\hline Preposition & o & $0.0 \%$ & o & $0.0 \%$ & o & $0.0 \%$ \\
\hline Pronoun & o & $0.0 \%$ & o & $0.0 \%$ & o & $0.0 \%$ \\
\hline Verb & 6 & $24.0 \%$ & 23 & $25.0 \%$ & 29 & $24.6 \%$ \\
\hline Depicting Sign & 14 & $56.0 \%$ & 56 & $60.9 \%$ & 78 & $66.1 \%$ \\
\hline Total & 25 & $100.0 \%$ & 92 & $100.0 \%$ & 118 & $100.0 \%$ \\
\hline
\end{tabular}


frequently used with verbs and depicting signs in L1 as well as L2 signers. Second, we see a level-related increased use of the A-type in L2 signers, i.e., they are approaching the target language use of adverbial mouth actions.

\section{Discussion}

This paper has used a corpus-based approach to explore the use of mouth actions in a group of hearing L2 learners of STS and compared this to L1 deaf signers. The primary motivation for such a study is to examine L2 learners' use and acquisition of mouth actions and to investigate the role of mouthing and its relation to the learners' L1. This motivation takes as a starting point the framework of cross-linguistic influence and the discussion of its role in SLA and how this can be applied to the acquisition situation of a new language in a different modality. But there is also a secondary motivation, which is to provide new insights regarding the nature of mouth actions in sign languages through ecological data from L2 groups with different proficiencies and compared to L1 signers.

First, we provided a descriptive analysis of the use of mouth actions across the learner groups and the L1 group, and our study revealed that L2 learners in many ways use mouth actions in a distribution rather similar to L1 signers but to a greater extent, that is, the ratio of mouth actions in relation to signs was higher in L2 signers compared to L1 signers. Furthermore, there are patterns that clearly differ from the L1 signers. L2 learners use mouthing, i.e., the M-type, which is derived from spoken language, to a greater extent than L1 signers do. For the other mouth categories associated with mouth gestures, i.e., the A-type, E-type, W-type, and 4-type as well as the backchanneling B-type, the greatest difference was noted for the A-type and the $\mathrm{W}$-type. On the one hand, the A-type was less frequently used among L2 learners, but its use seems to increase with time. On the other hand, L2 learners show an increased use of the $\mathrm{W}$-type compared to the $\mathrm{L}_{1}$ signers. We believe this is part of the gestural strategy that seems to be common among L2 SL learners. Regarding the A-type, we can think about this as a linguistic proficiency that needs to be learned over time. It should also be noted that in many cases, we have observed qualitative differences in the use of the A-type mouth action related to learner variability and L1 variability, which could be an interesting topic to examine more thoroughly. For instance, we have observed that some (but not all) L2 learners consistently use no mouth action at all in retellings. However, we suspect this is instead of using adverbial mouth actions, which was noted in the individual variation analysis.

Regarding no mouth action, our results revealed that L1 signers' signs were not accompanied by a mouth action one quarter of the time. This is interesting. 
On the other hand, L2 signers seem to rely on the use of mouth actions to a greater degree. In our analysis, we found that $\mathrm{L} 2$ learners exhibit a higher degree of indefinite mouth actions. This seems to decrease with proficiency, that is, the more proficient L2 signers exhibit fewer indefinite mouth actions. We believe this is associated with simultaneity and articulation skills, as learners have to focus on the signing, during which additionally controlling mouth actions can pose a challenge. Phenomena like the strong use of the M-type have been considered one of the indicators of disfluency in L2 signing.

Second, we performed an analysis of individual variation in the use of mouth actions. This study showed a clear account for individual variation in mouth actions in the L2 group but there were fewer differences in the rate of mouth actions in the L1 group. All L2 learners showed high frequency in their M-type use and almost no use of ME-type. It was also revealed that some learners (but not all) showed a decrease in their use of M-type with time. We see this as a developmental pattern in their acquisition. Over time, we also observe an increase in no mouth action as well as fewer occurrences of indefinite mouth actions. We think some learners have developed an awareness of how mouth actions are used in the target language: it is possible that some learners acquire mouth actions later due to the challenge of simultaneity. This needs to be studied further.

Third, we have also observed a pattern related to the interaction and synchronization of mouthing and hand movements among L2 learners of STS, in comparison to the control group with STS as its L1. It emerged clearly that the use of regressive and progressive spreading of mouth actions was nearly absent in the L2 group. This suggests a difference in prosodic skills, i.e., use of mouth actions for marking prosodic structure, which has not yet been acquired by L2 signers. Finally, our data demonstrate that L2 learners approach the mouth action patterns of L1 signers over time, at least in the retelling part of the study. Data for early learners versus late learners show a clear progression in the acquisition of mouth action patterns.

Lastly, we also performed an analysis of the correlation between the most frequent mouth actions used (A/M/ME-types) and grammatical class, i.e., parts of speech. A similar distribution was identified across the L2 groups and the L1 group, with some quantitative differences. Mouthing (i.e., M-type) was clearly most commonly associated with nouns, especially in the L1 group, whereas its use was slightly more common with verbs in the L2 groups. For the A-type, which was more closely associated with depicting verbs (classifier constructions) and verbs, no clear difference between groups could be detected.

Regarding the role of cross-linguistic influence and transfer, our data show that L2 learners tend to overuse mouthing due to the possibility of borrowing elements from their L1, spoken Swedish. We therefore believe that the mouth could 
serve as a possible channel for any cross-linguistic influence from L1 Swedish. Results presented here show similarities with the mouth patterns reported in Boyes Braem (2001) for deaf late signers. We have noted that L1 signers tend to use reduced mouthing in comparison to L2 learners, e.g., the ME-type. We note the greater amount of mouthing in the L2 group in comparison to the L1 group, and suggest that this is diminishing over time and with higher proficiency. However, to what extent this can be described in terms of transfer, i.e., what exactly is transferred, is complicated. Our suggestion is that mouthings are a form of articulation transfer or a kind of phonological transfer, at least in a very broad sense (and on an abstract level). With phonological transfer, we mean that the learner's knowledge and proficiency of speech in a language influence the learner's linguistic production based on the structure of the sounds and how they are articulated in speech. Clearly, most often learners benefit from this, as around 3/4 of their signs are accompanied by mouthings, which are close to their L1 Swedish and thus contribute to positive transfer. However, the overgeneralization of mouthings in earlier phases of learning also contributes to a sense of disfluency experienced by L1 signers. Furthermore, the lack of use of ME-type emphasizes the fact that the learners are not able to differentiate between the mouthing categories. This is possibly due to some nature of arbitrariness regarding which signs are accompanied by an obligatory $\mathrm{ME}$ action or not, which leads to an unintentional transfer of full mouthing (i.e., M-type) for all signs that have mouthing. We also noted many examples of mouthings that include Swedish inflections for tense, definiteness, or number, which strengthens the overuse of mouthing and contributes to disfluency. This clearly has implications for teaching. Taken together, the use of mouthings needs to be studied more carefully through qualitative analysis, a study which is currently in progress by the authors, in order to develop a better understanding of the details of the transfer process.

For future research into mouthing, it would also be useful to compare the productions of the L2 group with those of deaf L2 learners of STS (i.e., L2M1 learners), since the latter do not have Swedish as an L1 (and thus should lack this type of possible transfer from Swedish).

Regarding the second motivation of the study, our STS data in many ways confirm earlier findings on mouth actions reported for other sign languages. Among other things, mouthing is clearly the most frequent category of mouth actions, independent of the signers' proficiency level or linguistic background. Here, we expanded our description of mouthing to include the ME-type, that is, a reduced mouthing based on the same principles as the mono- or bisyllabic E-type. We found that L1 signers clearly use this variant of mouthing to a greater extent than the M-type. More studies concerning the association between the ME-type and signs are needed, but our preliminary observation is that some instances of 
the ME-type are associated with specific lexical signs, just as E-type mouthings are associated with signs as part of the sign construction, i.e., on the phonological level. Some individual variation linked to the M/ME-type also calls for more research.

Apart from the ME-type, we also observed that the A-type and E-type mouth gestures are less frequently used by L2 learners, which indicates that these mouth gestures are something that must be learned. We think this has implications for L2 sign language teaching. Furthermore, our tagging of "No mouth action" revealed some interesting results, namely that L1 signers consistently exhibit a large part of no mouth action in their signing, which was not the case with the L2 learners. Finally, it was shown that the use of mouth action categories differs depending on discourse types. In retellings, the A-type was more frequently used compared to interview data, whereas the M-type and E-type were more frequent in the interview data. The L2 group seems to follow this pattern as well.

To conclude, the results of our study have been based on quantitative corpus data. This is interesting given the strength of corpus data to compare different outcomes of mouth actions. For future research, it would be valuable to have a closer look at the qualitative differences revealed by the data between the L2 groups as well as the L1 group, especially with regard to the A-type, and in particular to investigate how the L2 learners are progressing with producing mouth actions together with the manual signs.

\section{Funding}

This article is the result of the project "From Speech to Sign - learning Swedish Sign Language as a Second Language" funded by Riksbankens Jubileumsfond (RJ) (P16-0371:1, PI: K. Schönström).

\section{Acknowledgements}

We would like to thank all of the informants who were involved in the project for their valuable contribution to research on second language acquisition of a signed language. We would also like to thank Josefin Bark, Ylva Larsson, Moa Gärdenfors, Joel Bäckström, and Nikolaus Riemer Kankkonen for assisting us in the annotation of the data and the construction of the corpus, and the anonymous reviewers for their valuable comments on earlier drafts of the paper. 


\section{References}

Anderson, Diane E. \& Judy S. Reilly. 1998. PAH! The acquisition of adverbials in ASL. Sign Language \& Linguistics 1(2). 117-142. https://doi.org/10.1075/sll.1.2.03and

Bank, Richard, Onno Crasborn \& Roeland van Hout. 2015. Alignment of two languages: The spreading of mouthings in Sign Language of the Netherlands. International Journal of Bilingualism 19(1). 40-55. https://doi.org/10.1177/1367006913484991

Bank, Richard, Onno Crasborn \& Roeland van Hout. 2016. The prominence of spoken language elements in a sign language. Linguistics 54(6). 1281-1305. https://doi.org/10.1515 /ling-2016-0030

Bauer, Anastasia. 2019. When words meet signs: A corpus-based study on variation of mouthing in Russian Sign Language. In Anastasia Bauer \& Daniel Bunčić (eds.), Linguistische Beiträge zur Slavistik, Specimina philologiae Slavicae 198. 9-35.

Bergman, Brita \& Lars Wallin. 2001. A preliminary analysis of visual mouth segments in Swedish Sign Language. In Penny Boyes Braem \& Rachel Sutton-Spence (eds.), The hands are the head of the mouth: The mouth as articulator in sign language, 51-68. Hamburg: Signum.

Bergman, Brita \& Lars Wallin. 2003. Noun and verbal classifiers in Swedish Sign Language. In Karen Emmorey (ed.), Perspectives on classifier constructions in sign languages, 35-51. Mahwah, NJ: Lawrence Erlbaum.

Bochner, Joseph H., Karen Christie, Peter C. Hauser \& J. Matt Searls. 2011. When is a difference really different? Learners' discrimination of linguistic contrasts in American Sign Language. Language Learning 61(4). 1302-1327. https://doi.org/10.1111/j.1467-9922.2011.00671.x

Börstell, Carl, Mats Wirén, Johanna Mesch \& Moa Gärdenfors. 2016. Towards an annotation of syntactic structure in the Swedish Sign Language Corpus. In Eleni Efthimiou, StavroulaEvita Fotinea, Thomas Hanke, Julie Hochgesang, Jette Kristoffersen \& Johanna Mesch (eds.), Workshop Proceedings: 7 th Workshop on the Representation and Processing of Sign Languages: Corpus Mining, 19-24. Paris: ELRA.

Boyes Braem, Penny. 2001. Functions of the mouthings in the signing of deaf early and late learners of Swiss German Sign Language (DSGS). In Penny Boyes Braem \& Rachel Sutton-Spence (eds.), The hands are the head of the mouth: The mouth as articulator in sign languages, 99-132. Hamburg: Signum Press.

Boyes Braem, Penny \& Rachel Sutton-Spence (eds.). 2001. The hands are the head of the mouth: The mouth as articulator in sign languages. Berlin: Signum Press.

Brennan, Mary. 1992. The visual world of BSL: An introduction. In David Brien (ed.), Dictionary of British Sign Language/English, 1, 1-133. London: Faber \& Faber.

Chen Pichler, Debbie \& Elena Koulidobrova. 2016. Acquisition of sign language as a second language. In Marc Marschark \& Patricia E. Spencer (eds.), The Oxford handbook of Deaf studies in language, 218-230. Oxford: Oxford University Press.

Council of Europe. 2001. Common European Framework of Reference for Languages: Learning, teaching, assessment. Strasbourg: Council of Europe.

Crasborn, Onno, Els van der Kooij, David Waters, Bencie Woll \& Johanna Mesch. 2008. Frequency distribution and spreading behavior of different types of mouth actions in three sign languages. Sign Language \& Linguistics 11(1). 45-67. https://doi.org/10.1075/sl\&amp;l.11.1 .04cra 
Crasborn, Onno, Johanna Mesch, Dafydd Waters, Els van der Kooij, Bencie Woll \& Brita Bergman. 2007. Sharing sign language data online: Experiences from the ECHO project. International Journal of Corpus Linguistics 12(4). 535-562. https://doi.org/10.1075/ijcl.12.4 .06cra

Ebbinghaus, Horst \& Jens Hessmann. 2001. Sign language as multidimensional communication: Why manual signs, mouthings, and mouth gestures are three different things. In Penny Boyes Braem \& Rachel Sutton-Spence (eds.), The hands are the head of the mouth. The mouth as articulator in sign language, 133-151. Hamburg: Signum Press.

Emmorey, Karen, Helsa B. Borinstein, Robin Thompson \& Tamar H. Gollan. 2008. Bimodal bilingualism. Bilingualism: Language and Cognition 11(1). 43-61. https://doi.org/10.1017 /S1366728907003203

Emmorey, Karen, Robin Thompson \& Rachael Colvin. 2009. Eye gaze during comprehension of American Sign Language by native and beginning signers. Journal of Deaf Studies and Deaf Education 14(2). 237-243. https://doi.org/10.1093/deafed/enno37

Ferrara, Lindsay \& Anna-Lena Nilsson. 2017. Describing spatial layouts as an L2M2 signed language learner. Sign Language \& Linguistics 20(1). 1-26. https://doi.org/10.1075/sll.20.1.01fer

Giustolisi, Beatrice, Emiliano Mereghetti \& Carlo Cecchetto. 2017. Phonological blending or code mixing? Why mouthing is not a core component of sign language grammar. Natural Language and Linguistic Theory 35(2). 347-365. https://doi.org/10.1007/s11049-016-9353-9

Gulamani, Sannah, Chloë Marshall \& Gary Morgan. 2020. The challenges of viewpoint-taking when learning a sign language: Data from the 'frog story' in British Sign Language. Second Language Research. https://doi.org/10.1177/0267658320906855

Gullberg, Marianne. 1998. Gesture as a communication strategy in second language discourse: A study of learners of French and Swedish. Lund: Lund University Press.

Gullberg, Marianne, Kees De Bot \& Virginia Volterra. 2008. Gestures and some key issues in the study of language development. Gesture 8(2). 149-179. https://doi.org/10.1075/gest.8.2.o3gul

Jarvis, Scott. 2015. The scope of transfer research. In Liming Yu \& Terence Odlin (eds.), New perspectives on transfer in second language learning, 17-48. Bristol: Multilingual Matters. https://doi.org/10.21832/9781783094349-004

Jarvis, Scott \& Aneta Pavlenko. 2008. Crosslinguistic influence in language and cognition. London: Routledge. https://doi.org/10.1017/Sooo8413100001109

Johnston, Trevor, Jane van Roekel \& Adam Schembri. 2016. On the conventionalization of mouth actions in Australian Sign Language. Language and Speech 59(1). 3-42. https://doi .org/10.1177/0023830915569334

Johnston, Trevor \& Adam Schembri. 2007. Australian Sign Language: An introduction to sign language linguistics. Cambridge: Cambridge University Press. https://doi.org/10.1017 /CBO9780511607479

Lewin, Donna \& Adam C. Schembri. 2011. Mouth gestures in British Sign Language: A case study of tongue protrusion in BSL narratives. Sign Language \& Linguistics 14(1). 94-114. https://doi.org/10.1075/sll.14.1.06lew

Liddell, Scott K. 1980. American Sign Language syntax. The Hague: Mouton.

Marshall, Chloe \& Gary Morgan. 2015. From gesture to sign language: Conventionalization of classifier constructions by adult hearing learners of British Sign Language. Topics in Cognitive Science 7(1). 61-8o. https://doi.org/10.1111/tops.12118

Mayberry, Rachel I. 2006. Second language learning of sign languages. In Keith Brown (ed.), Encyclopedia of language and linguistics, 743-746. Oxford: Elsevier. https://doi.org/10.1016 /Bo-08-044854-2/05260-3 
Mesch, Johanna \& Krister Schönström. 2018. From design and collection to annotation of a learner corpus of sign language. In Mayumi Bono, Eleni Efthimiou, Stavroula-Evita Fotinea, Thomas Hanke, Julie Hochgesang, Jette Kristoffersen, Johanna Mesch \& Yutaka Osugi (eds.), Proceedings of the 8th Workshop on the Representation and Processing of Sign Languages: Involving the Language Community [Language Resources and Evaluation Conference (LREC)], 121-126. Paris: ELRA.

Mesch, Johanna \& Lars Wallin. 2015. Gloss annotations in the Swedish Sign Language Corpus. International Journal of Corpus Linguistics 20(1). 102-120. https://doi.org/10.1075/ijcl.20.1 .05mes

Mirus, Gene, Christian Rathmann \& Richard P. Meier. 2001. Proximalization and distalization of sign movement in adult learners. In Valerie Dively, Melanie Metzger, Sarah F. Taub \& Anne Marie Baer (eds.), Signed languages: discoveries from international research, 103-119. Washington, DC: Gallaudet University Press.

Ortega, Gerardo. 2013. Acquisition of a signed phonological system by hearing adults: The role of sign structure and iconcity. London: University College London $\mathrm{PhD}$ dissertation.

Ortega, Gerardo \& Gary Morgan. 2015a. Phonological development in hearing learners of a sign language: The influence of phonological parameters, sign complexity, and iconicity. Language Learning 65(3). 660-688. https://doi.org/10.1111/lang.12123

Ortega, Gerardo \& Gary Morgan. 2015b. The effect of iconicity in the mental lexicon of hearing non-signers and proficient signers: evidence of cross-modal priming. Language, Cognition and Neuroscience 3o(5). 574-585. https://doi.org/10.1080/23273798.2014.959533

Ortega, Gerardo \& Gary Morgan. 2015c. Input processing at first exposure to a sign language. Second Language Research 31(4). 443-463. https://doi.org/10.1177/0267658315576822

Ortega, Gerardo, Annika Schiefner \& Aslı Özyürek. 2019. Hearing non-signers use their gestures to predict iconic form-meaning mappings at first exposure to signs. Cognition 191. 103-996. https://doi.org/10.1016/j.cognition.2019.06.008

Racz-Engelhardt, Szilard. 2016. Morphological properties of mouthings in Hungarian Sign Language (MJNY). Hamburg: University of Hamburg PhD dissertation. https://doi.org/10.1075 /sll.ooor6.eng

Ringbom, Håkan \& Scott Jarvis. 2009. The importance of cross-linguistic similarity in foreign language learning. In Michael H. Long \& Catherine J. Doughty (eds.), The handbook of language teaching, 106-118. Oxford: Wiley Blackwell. https://doi.org/10.1002/9781444315783 .ch7

Rosen, Russell S. 2004. Beginning L2 production errors in ASL lexical phonology: A cognitive phonology model. Sign Language \& Linguistics 7(1). 31-61. https://doi.org/10.1075/sll.7.1 .o4beg

Schönström, Krister \& Johanna Mesch. 2017. Dataset. The project 'From speech to sign - learning Swedish Sign Language as a second language'. Department of Linguistics, Stockholm University.

Sutton-Spence, Rachel \& Bencie Woll. 1999. The linguistics of British Sign Language: An introduction. Cambridge: Cambridge University Press. https://doi.org/10.1017/CBO9781139167048

Wallin, Lars \& Johanna Mesch. 2018. Annoteringskonventioner för teckenspråkstexter. Version 6, januari 2018. [Annotation guidelines for sign language texts]. Department of Linguistics, Stockholm University. 


\section{Address for correspondence}

Krister Schönström

Department of Linguistics

Stockholm University

10691 Stockholm

Sweden

schonstrom@ling.su.se

\section{Co-author information}

Johanna Mesch

Department of Linguistics

Stockholm University

johanna.mesch@ling.su.se

\section{Publication history}

Published online: 8 December 2020

Corrected: 11 December 2020

In the original Online-First version of this article published on 8 December 2020, the address for correspondence was incorrect. This has been updated in the current version of the article. 